\title{
FINANÇAS COMPORTAMENTAIS: ANÁLISE DOS FATORES DO EFEITO MANADA EM EMPRESAS LISTADAS NA [B] $]^{3}$
}

\author{
BEHAVIORAL FINANCE: HERD BEHAVIOR ANALYSIS ON $[B]^{3}$ LISTED \\ COMPANIES
}

\author{
VANESSA MENESES SILVA \\ Universidade Federal da Paraíba. Endereço: Campus I - Lot. Cidade \\ Universitaria | 58051-900| João Pessoa/PB | Brasil. \\ (D) http://orcid.org/0000-0002-6045-2143 \\ vanessa_m.s@outlook.com
}

\author{
WENNER GLAUCIO LOPES LUCENA \\ Universidade Federal da Paraíba. Endereço: Campus I - Lot. Cidade \\ Universitaria | 58051-900| João Pessoa/PB | Brasil. \\ (1) http://orcid.org/0000-0002-2476-7383 \\ wdlucena@yahoo.com.br
}

\section{RESUMO}

Este trabalho baseou-se na Teoria do Prospecto (Kahneman \& Tversky, 1979), sob a ótica da heurística do efeito manada, e teve como objetivo geral investigar a relação entre a crise do subprime, a publicação de notícias e o tamanho da empresa com comportamento manada nas 100 companhias com os maiores volumes de negociações listadas na $[\mathrm{B}]^{3}-$ Brasil Bolsa Balcão, no período de 2007 a 2016. A fim de alcançá-lo, foi utilizado inicialmente como metodologia o modelo de cross-sectional absolute deviation of returns (CSAD), proposto por Chang, Cheng e Khorana (2004), para a identificação da presença do efeito manada. As relações entre as variáveis foram analisadas por meio da regressão do modelo de dados em painel com efeitos fixos e errospadrão robustos. De maneira geral, os resultados encontrados indicaram a existência de relação positiva entre o comportamento manada, a crise do subprime e a publicação de notícias boas; entretanto, revelou uma relação negativa com o tamanho da empresa. Para a variável Notícias Ruins os resultados não evidenciaram significância estatística (p-valor $>0,26$ ), por isso a hipótese de existência de relação negativa entre o efeito manada e a publicação de notícias ruins foi rejeitada. Diante disso, entende-se que os investidores são influenciados pelas notícias positivas referentes às empresas, e isto tende a gerar neles um comportamento de investimento semelhante ao apresentado pelos grupos maiores de investidores, ou seja, o efeito manada.

Palavras-chave: Efeito Manada. Crise. Notícias.

\begin{abstract}
We based our work on the Prospect Theory (Kahneman \& Tversky, 1979), from the heuristic perspective of the herd effect, and our general objective was to investigate the relationship between the subprime crisis, the news publication and the size of the company with behavior herd in the 100 companies with the largest trading volumes listed on the $[B]^{3}-$ Brazilian Stock Exchange, from 2007 to 2016. In order to achieve this, we initially employed, as methodology, the cross-sectional absolute deviation of returns (CSAD) model, proposed by Chang, Cheng and
\end{abstract}


Khorana (2004), to identify the presence of the herd effect. The relationships among the variables were analyzed through the regression of the panel data model with fixed effects and robust standard errors. In general, the results found indicated a positive relationship among the herd behavior, the subprime crisis and the publication of good news; however, revealed a negative relationship with the size of the company. For the Bad News variable, the results did not show statistical signifimayce ( $p$-value > 0.26), so the hypothesis of a negative relationship between the herd effect and the bad news was rejected. Concluding, investors are influenced by the positive news about companies, and this tends to generate in them an investment behavior similar to that presented by the larger groups of investors, i.e., the herd effect.

Keywords: Herd Effect. Crisis. News.

\section{INTRODUÇÃO}

As Finanças são consideradas um dos pilares das organizações, pois antes das principais decisões empresariais, os gestores buscam fazer uma análise acurada da sua situação financeira. Dentro das finanças existem algumas vertentes de pensamentos, tais como a das Finanças Tradicionais, que se constituiu a partir de uma abordagem microeconômica, tendo, como paradigma central, a utilização total da racionalidade nas decisões financeiras, por parte dos agentes econômicos. Além desta, existem as Finanças Modernas, fundamentadas no modelo financeiro da Hipótese de Eficiência do Mercado (HEM), que se baseia no retorno máximo esperado e nas expectativas racionais, considerando que os investidores ordenam de forma lógica e racional suas preferências, buscando maximizar os retornos de seus investimentos (Lucena, Santos \& Assis; Santos, 2014).

São evidentes as contribuições trazidas por essas correntes de pensamento; no entanto, após a ocorrência de alguns desequilíbrios financeiros, tais como a crise financeira do subprime ${ }^{1}$, evidenciada no ano de 2008, alguns de seus aspectos foram repensados, como a Hipótese de Eficiência do Mercado (HEM), que afirma que as decisões tomadas pelos investidores são sempre racionais e baseadas na maximização do retorno esperado.

A eficiência de mercado considera a existência de homogeneidade de expectativas, racionalidade e informações, ou seja, ela estrutura-se na não existência de irracionalidade, de assimetria informacional entre os agentes, ou de ganhos anormais frequentes de uma pessoa ou grupo específico (Barberis \& Thaler, 2003). No entanto, ao se observar os retornos de mercado e o comportamento dos investidores, percebe-se que é improvável a ocorrência desse ambiente com total eficiência no mercado financeiro.

Em vista disso, as correntes de pensamento em Finanças Comportamentais têm emergido e ganhado notoriedade, com diversas pesquisas e teorias que consideram fatores cognitivos para explicar algumas decisões tomadas pelos stakeholders. Dentre elas está a Prospect Theory, proposta por Kahneman e Tversky (1979), que fez com que o psicólogo Daniel Kahneman ganhasse o prêmio Nobel de Economia em 2002, juntamente com o neuroeconomista Vernon L. Smith, da Universidade George Mason, reconhecido por ter conseguido ligar as experiências laboratoriais à análise empírica da economia e, especialmente, ao estudo dos mecanismos alternativos do mercado financeiro.

$\mathrm{Na}$ mesma linha de pensamento da Teoria do Prospecto, existe a heurística do comportamento $^{2}$ manada, que, por sua vez, descreve como os investidores tendem a tomar decisões

\footnotetext{
${ }^{1}$ Crise financeira desencadeada a partir de meados do ano de 2007, com a queda do índice Dow Jones, que se deu devido à deliberada concessão de empréstimos hipotecários de alto risco e à inadimplência por parte dos tomadores desses empréstimos. Essa prática prejudicou significativamente vários bancos, deixando-os em uma situação de insolvência, o que provocou uma retração na economia e repercutiu nas bolsas de valores de todo o mundo.

2 Neste trabalho, as palavras "efeito" e "comportamento" devem ser entendidas com o mesmo significado, pois a heurística do efeito manada trata de uma expressão do comportamento.
} 
sem uma orientação planejada racionalmente, apenas influenciados por decisões de outros investidores. Ou seja, ele ocorre quando o comportamento de um grupo de investidores imita o comportamento de outro de forma irracional, ignorando suas próprias análises e percepções do mercado (Sanches, 2013).

Ainda no que diz respeito ao tema, Silva, Barbedo e Araújo (2015) afirmam que o efeito manada ocorre quando determinado grupo de investidores negocia o mesmo ativo na mesma direção do mercado, em um certo período de tempo, desconsiderando suas próprias experiências, informações e crenças a respeito dos valores dos ativos. Com isso, esse efeito pode ser considerado nocivo, pois tende a ocasionar perdas de informações e distorções na informação agregada ao mercado (Bikhchandani, Hirshleifer \& Welch, 1992; Bannerjee, 1992).

Por meio da observação da literatura relacionada ao tema, percebe-se que vários autores buscaram analisar os fatores que podem se relacionar com a ocorrência do efeito manada. Encontrou-se diversos trabalhos, nacionais e internacionais, tratando da influência de variáveis como: a opinião de analistas, os retornos financeiros e o nível de liquidez das ações (Christie \& Huang, 1999; Chang, Cheng \& Khorana, 2004; Kutcukian, Dana \& Eid Jr, 2010; Araujo Neto, Serrano, Oliveira Neto \& Freitas, 2016).

Keynes (1936) percebeu que o efeito manada também pode ser percebido em alguns eventos presentes no cotidiano de várias pessoas, como na escolha de restaurantes, lojas e marcas, que é, geralmente, influenciada pelo nível de popularidade, em que se identifica cada opção de escolha e, ao final, opta-se pela considerada mais popular. Da mesma maneira, esse efeito pode ser observado ao analisar-se a forma como os agentes do mercado acionário se comportam perante as decisões dos demais agentes.

A partir dessa perspectiva, o trabalho desenvolvido por $\mathrm{Fu}$ e Lin (2010) verificou a ocorrência de reações assimétricas às boas e más notícias referentes aos retornos mensais do mercado de ações da China. Por meio da pesquisa deles, foi confirmada a presença do efeito manada em condições extremas de mercado. Concomitantemente, Yao, Ma e He (2014) analisaram a diferença na incidência do efeito manada em investidores chineses e investidores de outras nacionalidades nas bolsas de valores de Xangai e de Shenzhen. Em sua pesquisa, Tariki (2014) verificou a existência de relação entre a intensidade do efeito manada e o tamanho dos fundos de investimentos.

Um outro aspecto relacionado ao comportamento manada é a crise financeira. Dentro dessa perspectiva, Dzielinski (2011) examinou que durante momentos de incertezas econômicas, como os provocados pelas crises financeiras, os investidores estão expostos a um maior volume de notícias desfavoráveis e inesperadas sobre as companhias, e isto tende a promover maior insegurança, levando-os a desconsiderar suas análises e informações pessoais e a buscar um comportamento semelhante ao dos outros investidores.

Diante do exposto, percebe-se que os estudos relacionados às finanças comportamentais têm conquistado espaço no meio científico, pois cada vez mais tem se evidenciado a importância de se analisar os diversos aspectos que influenciam a tomada de decisões dos agentes que compõem o mercado financeiro. Com isso, considerou-se pertinente no desenvolvimento deste trabalho realizarmos uma análise das razões que podem explicar o comportamento dos agentes integrantes do mercado financeiro brasileiro, pois as suas decisões são determinantes para o próprio funcionamento do mercado.

Vários autores apontaram que fatores cognitivos tendem a influenciar nesse processo decisório. Tendo em vista que os estudos evidenciaram uma tendência do comportamento dos investidores em se assemelhar aos padrões adotados por determinado grupo, explicando, com isso, a existência do efeito manada, considerou-se pertinente investigar os fatores explicativos deste comportamento, bem como analisar como se dá a relação entre eles e tal comportamento. Assim, sugeriu-se o seguinte problema de pesquisa: Qual é a relação existente entre a crise do subprime, 
a publicação de notícias e o tamanho da empresa, com a ocorrência do efeito manada nas companhias com os maiores volumes de negociações listadas na $[B]^{3}$ - Brasil Bolsa Balcão?

A importância desta pesquisa se dá por sua provável contribuição para a construção do entendimento das Finanças Comportamentais, dos fatores que interferem nas decisões do mercado financeiro, como também para a identificação de possíveis relações entre variáveis que podem explicar o comportamento dos agentes que compõem esse mercado. Outra contribuição observada diz respeito às informações levantadas neste trabalho, que podem fomentar o desenvolvimento de novas pesquisas relacionadas ao tema.

Ademais, várias pesquisas dentro desta temática foram realizadas, a maioria delas buscando identificar o efeito manada focado no comportamento das instituições (Almeida, 2011; Araujo Neto; Freire, 2013; Araujo Neto et al., 2016). Diferente dos demais, este trabalho buscou não apenas verificar a ocorrência do efeito manada, mas também analisar alguns fatores que, possivelmente, se relacionam com a presença desse comportamento, tais como o período da crise financeira do subprime e a publicação de notícias relacionadas às empresas. A originalidade da pesquisa é evidenciada por esses fatores ainda não terem sido estudados em conjunto pelos demais autores que trataram dessa temática.

As próximas seções do trabalho foram estruturadas da seguinte forma: na seção 2 apresentamos o referencial teórico abordando a Teoria do Prospecto e aspectos da heurística do efeito manada; na seção 3, tratamos da metodologia utilizada no desenvolvimento do trabalho; na seção 4, são apresentados os resultados e suas respectivas análises e, por fim, na seção 5, relatamos as considerações finais da pesquisa.

\section{FUNDAMENTAÇÃO TEÓRICA}

\subsection{Finanças Comportamentais e a Teoria do Prospecto}

O estudo considerado de maior relevância na área de Finanças Comportamentais foi publicado no ano de 1979 pelos pesquisadores Daniel Kahneman e Amos Tversky, com o título "Prospect Theory: analysis of decision under risk". Nele, os autores investigaram o comportamento, as ações e o processo de tomada de decisão dos investidores em situações que envolviam os riscos presentes no dia a dia do mercado financeiro (Passos, Pereira \& Martins, 2012). A partir dos resultados obtidos, foi desenvolvida a Teoria do Prospecto, na qual os autores incorporaram o julgamento heurístico ao processo de decisão dos investidores. O desenvolvimento dessa teoria rendeu a Kahneman o prêmio Nobel de Economia no ano de 2002. Com isso, as Finanças Comportamentais começaram a conquistar espaço e notoriedade.

A Teoria do Prospecto considera que as probabilidades adotadas nas finanças devem ser substituídas por pesos de decisão e que estes valores precisam ser atribuídos aos ganhos e às perdas em vez de serem relacionados aos resultados finais. A partir daí, a função de valor é tida como côncava no domínio dos ganhos e convexa no domínio das perdas. Na maioria das vezes, a função termina sendo mais inclinada para os resultados negativos do que para os positivos. Os pesos atribuídos às decisões são inferiores às suas probabilidades, exceto nas situações em que a probabilidade de ocorrência é muito baixa (Kahneman \& Tversky, 1979).

Dentro dessa temática, Ricciardi e Simon (2000) relataram em seu estudo que as Finanças Comportamentais procuram explicar os padrões de raciocínio dos investidores, englobando os processos emocionais envolvidos e seu nível de interferência no processo de tomada de decisões. Afirmam também que as Finanças Comportamentais buscam analisar os fatores psicológicos e sociológicos que influenciam as tomadas de decisões financeiras dos indivíduos, grupos e entidades.

A evolução de estudos nessa área do conhecimento possibilitou o aperfeiçoamento do Modelo Moderno de Finanças, pois agregou a este os resultados de pesquisas sobre o comportamento e a irracionalidade dos agentes que compõem o mercado, que agora podem ser 
reconhecidos como indivíduos cujas ações e decisões recebem a influência de emoções e erros cognitivos, fazendo com que percebam as situações de diferentes formas, em função do modo como analisam as questões (Halfed \& Torres, 2001).

Percebe-se que a Teoria do Prospecto proporciona a identificação das diferenças comportamentais nos investidores diante das perdas e dos ganhos, como a sua disposição em se expor mais a riscos com o intuito de recuperar perdas passadas e a tendência de buscar reverter posições anteriores para alcançar lucros elevados (Kimura, 2003).

Conforme afirma Arruma (2006), as Finanças Comportamentais referem-se a uma abordagem diferenciada para o estudo do mercado financeiro e, particularmente, para a análise do comportamento do investidor, reagindo às possíveis falhas observadas no modelo considerado pela Moderna Teoria de Finanças. Outrossim, Sewell (2007) afirma que as Finanças Comportamentais são uma vertente de estudo em que se analisa a influência de aspectos psicológicos no comportamento dos agentes e suas implicações no mercado financeiro.

Corroborando com o tema, Rogers et al (2007), sugeriram em seu trabalho que os aspectos comportamentais são preponderantes na tomada de decisões. Ariely (2008) enfatiza que a análise de parâmetros comportamentais anteriores é utilizada como base de referência no processo de decisão, e que a compreensão da informação apresentada sobre a realidade nem sempre se baseia no que realmente é verdadeiro, mas sim na concepção e representação que se tem dela. Ou seja, as decisões sofrem a influência de fatores cognitivos.

Conforme Leone e Guimarães (2012), o principal objetivo dos estudos na área de Finanças Comportamentais é identificar e compreender as ilusões cognitivas responsáveis pelos erros sistemáticos de avaliação dos investidores, a fim de adaptar os modelos econômico-financeiros, buscando orientar e capacitar os agentes econômicos para que suas tomadas de decisões ocorram de maneira mais adequada.

Para Lucena, Costa e Aragão (2013), a influência de aspectos psicológicos no comportamento humano tornou-se um importante viés a ser explorado, a partir da consideração de uma visão abrangente no que diz respeito ao entendimento do processo decisório e da relação entre a racionalidade e a irracionalidade nesse processo.

Tendo em vista que os modelos de Finanças Comportamentais consideram a influência dos aspectos psicológicos dos seres humanos e reconhecem a possibilidade de irracionalidade nas decisões dos agentes, eles podem atuar no preenchimento das lacunas teóricas observadas na Moderna Teoria de Finanças. Pois, de acordo com Silva, Barbedo e Araujo (2015), as Finanças Comportamentais utilizam conceitos provenientes de vários campos do conhecimento, tais como a Psicologia, a Economia e as Finanças, com o propósito de desenvolver modelos de mercado mais complexos e incorporar vieses cognitivos que podem influenciar nas tomadas de decisões. Diante disso, percebe-se que diversos estudos foram realizados nesse sentido e evidenciaram que, em várias situações, o comportamento dos agentes econômicos se distancia, significativamente, da racionalidade abordada pela Moderna Teoria de Finanças. Almeida (2011) afirma que é inegável o fato de o ser humano utilizar de forma limitada sua capacidade de raciocínio, principalmente quando se trata de decisões referentes a questões complexas envolvendo outras pessoas.

Apesar de alguns autores da área de Finanças considerarem as Finanças Comportamentais como uma corrente de pensamento que vai de encontro às Finanças Modernas (Kutchukian, 2010; Barros, 2005; Borsato, Costa, Pimenta \& Ribeiro, 2009), buscou-se para esse trabalho um posicionamento no sentido de que elas podem contribuir para que os investidores sejam mais racionais a partir do estudo e da compreensão das ilusões cognitivas que podem influenciá-los.

\subsection{Heurística do Comportamento Manada}

Diversas heurísticas são estudadas dentro das Finanças Comportamentais. Dentre elas, encontra-se o comportamento manada ou "herding behavior" que, segundo Almeida (2011), refere-se ao comportamento que leva alguns investidores a ignorar suas informações pessoais para 
seguir a conduta de outros investidores. Esse efeito considera que o indivíduo busca seguir o comportamento e as decisões de um grupo movido pelo sentimento de que é melhor errar em conjunto do que sozinho (Passos, Pereira \& Martins, 2012). Bikhchandani e Sharma (2001) também o reconhecem como o movimento correlacionado de investidores, que apresentam decisões de investimentos semelhantes a determinado grupo.

O efeito manada no mercado financeiro também é caracterizado por uma homogeneização das ações dos seus participantes, que se comportam em um determinado momento da mesma forma. Ou seja, é quando um agente do mercado busca seguir um grupo ("rebanho") mesmo possuindo opinião divergente. (Toscani, 2006; Delitala \& Lorenzi, 2014). Para During, Juengel e Trussardi (2017) este comportamento é impulsionado por emoções e, geralmente, ocorre por causa da pressão social de conformidade. Outra causa apresentada é o apelo à crença de que é improvável que um grande número de pessoas possam estar erradas.

Alguns estudos sobre o efeito manada vêm sendo desenvolvidos. No âmbito internacional, Shih et al (2012) analisaram os mercados emergentes e identificaram o comportamento manada nas bolsas de valores do Pacífico em relação às operações nas bolsas de valores americanas. Semelhantemente, Chiang e Dazhi (2010) também encontraram evidências da ocorrência desse efeito nas bolsas de valores chinesas de Shenzhen e Xangai. Ainda, Chiao, Hung e Lee (2011), em seu estudo utilizando os dados intradiários das companhias, identificaram o efeito manada nas instituições que operam na bolsa de valores de Taiwan.

No que diz respeito ao Brasil, os resultados encontrados no estudo de Lobão e Serra (2002) sugerem a ocorrência de um nível mais elevado de efeito manada em mercados emergentes do que em mercados desenvolvidos. Kutchukian et al. (2010) observaram evidências de efeito manada em grupos de investidores com diferentes portes de investimentos em ações e investimentos de renda fixa. Almeida (2011), utilizando-se da metodologia sugerida por Christie e Huang (1999), investigou a possível ocorrência do efeito manada em mercados financeiros latino-americanos; no entanto, esse estudo não apresentou resultados consistentes que sugerissem a aceitação da hipótese de ocorrência do efeito manada. Da mesma forma, não foi verificada a presença do efeito manada no estudo de Sanches (2013), no qual foi utilizado o modelo proposto por Hwang e Salmon (2001 e 2004).

Seguindo a mesma linha de pensamento, o estudo de Schlender e Ceretta (2014) identificou a presença do comportamento manada por meio da análise dos retornos diários das ações de companhias relacionadas a cinco commodities $^{3}$ dos EUA. Assim como na pesquisa de Zhou e Anderson (2013), também foi detectado o comportamento manada por meio da observação de diferentes períodos de retornos (diários, semanais e mensais) em Fundos de Investimento Imobiliário nos anos de 1980 a 2010. Da mesma forma, no estudo desenvolvido por Cont e Bouchaud (2000) foi verificada a presença do efeito manada a partir do retorno sobre os ativos.

Uma das explicações para esse comportamento se dá pelo fato de os agentes, muitas vezes, terem suas performances avaliadas por meio da comparação com a performance do mercado. Por isso, os gestores não objetivam a maximização do resultado com a minimização do risco, mas buscam resultados semelhantes aos retornos de mercado, a fim de apresentarem uma avaliação satisfatória para seu próprio desempenho (Araujo Neto et al., 2016). Conforme Puckett e Yan (2008), outra justificativa para a ocorrência do efeito manada também pode ser atribuída à assimetria informacional presente no mercado financeiro, pois especula-se que os investidores imitam os demais ao observarem suas atitudes, acreditando que elas tenham alguma influência de conteúdo informacional implícito.

Vários motivos podem justificar, teoricamente, o fato de um indivíduo alterar suas decisões de investimento ao tomar conhecimento do comportamento de outros. (Lakonishok, Shleife \& Vishny, 1992; Christie \& Huang, 1999; Sias, 2004). Um deles é que o efeito manada indica a existência de informações adicionais sobre o mercado e, assim, esse comportamento ocorreria por

\footnotetext{
${ }^{3}$ São produtos ou mercadorias que possuem a funcionalidade de matéria-prima. No estudo de Schlender e Ceretta (2014) foram considerados o algodão, o café, o trigo, a soja e o açúcar.
} 
uma presunção de informação complementar relacionada ao mercado. Diante disso, entende-se que a divulgação de informações sobre as companhias tende a apresentar relação com a ocorrência do efeito manada.

Há também estudos que verificaram a existência da relação entre o efeito manada e os retornos das ações, como o de Cont e Bouchaud (2000), que concluiu que os investidores amadores apresentam o comportamento de manada. Tal efeito também pode ser explicado por reações similares dos investidores a choques e novas informações. Outrossim, Teh e DeBondt (1997) identificaram relação entre o efeito manada e os retornos, e perceberam que esse comportamento apresenta poder adicional de explicação da variância dos retornos das ações. Adicionalmente, outros fatores relacionados ao comportamento manada podem ser elencados: imperfeições nas informações de mercado, como o tamanho dos ativos; volume de negociação; feedback dos investidores de retornos passados; e gerenciamento de riscos (Kremer \& Nautz, 2013).

A fim de identificar os fatores explicativos do comportamento manada nos agentes participantes do mercado financeiro nacional, para este trabalho foram formuladas quatro hipóteses de pesquisa com base em estudos relacionados à temática proposta, tais como o estudo realizado por Araujo Neto et al. (2016) - que indicou que o processo de decisão não se utiliza estritamente da racionalidade, dado que considera também a influência das heurísticas de julgamento na alteração da forma de escolha racional de cada indivíduo -, e o trabalho desenvolvido por Silva, Barbedo e Araújo (2015), que detectou a existência do efeito manada em duas empresas listadas na $[\mathrm{B}]^{3}$ - Brasil Bolsa Balcão com elevados volumes de negociações.

Nesse contexto, destaca-se ainda que durante momentos de incertezas econômicas, como os provocados pelas crises financeiras, os investidores estão expostos a um maior volume de notícias negativas e inesperadas sobre as companhias (Dzielinski, 2011). Em seu estudo, Badhuri e Mahapatra (2013) aplicaram testes alternativos para obter a simetria nas distribuições de retorno no mercado acionário indiano e confirmaram uma maior presença de comportamento manada no período de crise financeira. Por isso, entendeu-se como necessária a análise da seguinte hipótese:

H1: Existe relação positiva entre a ocorrência do efeito manada e o período da crise do subprime nas empresas com os maiores volumes de negociações listadas na $[\mathrm{B}]^{3}-$ Brasil Bolsa Balcão.

Em busca de razões que esclareçam as movimentações do mercado financeiro, observa-se também que existe uma confiança por parte dos investidores na utilização das notícias, pois de acordo com Tibúrcio, Carvalho e Nunes (2012), os investidores tendem a acreditar que, quando suas decisões de investimentos se baseiam em notícias divulgadas sobre as empresas, pode ocorrer um aumento da probabilidade de obtenção de retornos sobre suas aplicações, ou seja, creem que por meio das notícias é possível prever, de forma confiável, os resultados futuros. Por isso, as informações publicadas sobre as companhias tendem a afetar o julgamento dos agentes, podendo ocasionar excesso de otimismo ou de pessimismo.

Cutler, Porteba e Summers (1989) mostraram, em sua pesquisa, que as variações observadas nas negociações e, consequentemente, nos preços das ações no mercado acionário, eram reflexo das notícias divulgadas sobre o mundo financeiro e econômico. Dentro dessa perspectiva, a pesquisa de Marsden, Veeraraghavan e Ye (2008) concluiu que a divulgação de notícias positivas referentes a companhias de capital aberto potencializa o otimismo dos analistas, fazendo com que eles façam previsões considerando aumentos exagerados em seus lucros. Do mesmo modo, o estudo realizado por Amir e Ganzach (1998) também deu indícios de que a exposição dos agentes econômicos a boas notícias tende a despertar o excesso de otimismo, podendo ocasionar um aumento nos erros de previsões dos retornos esperados sobre seus investimentos. Assim, formulase a hipótese de que: H2: Ocorre relação positiva entre a presença do efeito manada e a publicação de notícias boas referentes às empresas analisadas.

Para Tibúrcio et al (2012), as notícias sobre os acontecimentos políticos e econômicos também afetam, diretamente, a movimentação das bolsas de valores do mundo todo. Lam, DeRue, 
Karam e Hollenbeck (2011) afirmam que o recebimento de muitas notícias pode resultar em uma sobrecarga de informação, que tende a estimular o viés de aversão à perda, reduzindo, potencialmente, as atividades de negociação dos investidores durante os períodos de instabilidade.

O estudo realizado por Damodaran (2010) concluiu que a presença de notícias negativas tende a ocasionar um viés comportamental nos investidores avesso à perda. Diante disso, a fim de analisar a possível influência da publicação de notícias negativas com a ocorrência do efeito manada nas empresas que possuem os maiores volumes de negociações listadas na $[\mathrm{B}]^{3}-$ Brasil Bolsa Balcão, tem-se como hipótese de pesquisa: H3: Existe relação negativa entre a presença do efeito manada e a publicação de notícias ruins referentes às empresas analisadas.

No que diz respeito ao fator "tamanho do ativo", Lakonishok, Shleifer e Vishny (1992) investigaram o efeito manada no mercado de ações por meio dos ativos detidos em fundos americanos e encontraram uma evidência fraca de efeito manada em títulos de pouca capitalização; também identificaram poucas evidências de relação entre o tamanho das ações e o comportamento manada na amostra analisada. No entanto, Kremer e Nautz (2013), em seus estudos, também consideraram elementos como tamanho dos ativos, volume de negociações, feedback dos investidores de rendimentos anteriores e gestão de risco e de volatilidade e perceberam que os investidores amadores exibiram o comportamento de manada e que este se relacionou com o fator "tamanho do ativo"; além disso, concluíram que o efeito manada é mais provável de ocorrer em ações com maiores volumes de negociações no mercado, porque as instituições tendem a apresentar uma maior uniformidade na informação. Assim como Tariki (2014), que por meio da sua análise, encontrou indícios de que a intensidade do efeito manada varia de acordo com o tamanho do fundo de investimento. Ainda, os estudos de Choi e Sias (2009), e de Venezia, Nashikkar e Shapira (2011) confirmaram uma maior incidência do comportamento manada em pequenas entidades. Diante disso, essa variável foi considerada como variável de controle no modelo utilizado.

\section{METODOLOGIA}

A amostra analisada foi composta pelas cem empresas com os maiores volumes de negociações listadas na $[\mathrm{B}]^{3}$ - Brasil Bolsa Balcão. A escolha dessas empresas pode ser justificada pela sua representatividade na bolsa. Roth, Albuquerque e Silva (2012) evidenciaram que elas possuem alta representatividade e fazem parte da estruturação do Índice Bovespa (Ibovespa) e do IBrX100 4 , dois importantes índices que demonstram o desempenho médio do mercado. O período analisado englobou os anos de 2007 a 2016, ou seja, dez anos. A listagem das 100 empresas da $[\mathrm{B}]^{3}$ com os maiores volumes de negociações foi retirada do sítio eletrônico da própria bolsa de valores analisada, e a coleta das informações financeiras se deu por meio da base de dados da Thomson Reuters Eikon.

A coleta das variáveis sobre a publicação de notícias foi realizada utilizando-se a técnica de análise de conteúdo, pois foram observadas as publicações de informes sobre as empresas nos sites dos veículos Capital, Mercado \& Negócios, Valor Econômico e Folha de S.Paulo referentes aos anos estudados.

Para tanto, considerou-se que informações sobre a valorização das ações da empresa; aumento do lucro; melhoramento dos resultados; novos investimentos; desenvolvimento de projetos; fusões; aquisições; abertura de novas unidades; e recebimento de investimentos externos seriam notícias positivas. Por outro lado, fatores como diminuição do lucro; piora nos resultados (aumento dos prejuízos); problemas com a Justiça (multas, irregularidades, penalizações etc.); reclamações de clientes e a desvalorização das ações da empresa foram reconhecidas como notícias

\footnotetext{
${ }^{4}$ Refere-se ao Índice Brasil, um dos índices apresentados pela [B] ${ }^{3}$ - Brasil Bolsa Balcão, no qual demonstra-se o resultado de uma carteira teórica composta pelas ações das cem empresas mais negociadas nesta bolsa de valores.
} 
negativas. De maneira geral, foram identificadas as notícias que, possivelmente, influenciariam positiva e negativamente a imagem da empresa diante do investidor.

Afim de coletar as informações sobre as empresas, em cada jornal, individualmente, utilizouse uma variável dummy, adotando-se 0 para a ausência de notícias e 1 para a existência. A partir daí elas foram somadas, e atribuiu-se o valor 3 para as empresas que apresentaram notícias nos três jornais, 2 para as companhias cujas notícias foram encontradas em dois jornais, 1 para as empresas que apresentaram notícias apenas em um jornal, e 0 no caso de não existirem notícias sobre elas nos três jornais. Esse tratamento foi realizado tanto para a variável "Notícias Boas" quanto para "Notícias Ruins". Tal método foi utilizado visando evitar que a variável dummy se mantivesse constante ao longo do período e inibir a presença de multicolinearidade.

Para a identificação da ocorrência do efeito manada, foi utilizado o modelo desenvolvido por Chang et al. (2004), o cross-sectional absolute deviation of returns (CSAD), ou seja, a verificação por meio da utilização da média dos desvios-padrão absolutos de retornos, pois esta é considerada a melhor medida de dispersão. Este modelo considera a hipótese de que durante alguns períodos os investidores tendem a suprimir as suas próprias crenças e baseiam as suas decisões em ações coletivas e, por isso, os retornos tendem a se aproximar do retorno geral do mercado. Então, para este trabalho, todos os testes foram realizados considerando as médias dos desvios-padrão absolutos dos retornos, calculados por meio da fórmula do CSAD:

em que:

$$
C S A D_{t}=\frac{\sum\left|R_{i, t}-R_{m, t}\right|}{N-1}
$$

$C S A D_{t}=$ Médias dos desvios-padrão absolutos dos retornos;

$R_{i, t}=$ Retorno do ativo i no período t (retorno das ações);

$R_{m, t}=$ Retorno médio do mercado no período t;

$N=$ Quantidade de ativos analisados.

Mesmo existindo a opção de se verificar o comportamento manada por meio do desviopadrão transversal de retornos (CSSD), pelo fato de se tratar de uma medida intuitiva ele tende a ser mais sensível e influenciado pela presença de outliers (valores discrepantes). O modelo de regressão considera uma especificação quadrática para a relação entre CSAD e o retorno do mercado de acordo com a equação (2):

$$
C S A D_{t}=\propto+\gamma_{1}\left|R_{m, t}\right|+\gamma_{2} R_{m, t}^{2}+\varepsilon_{t}
$$

em que:

$\varepsilon_{t}=$ Os erros do modelo.

O raciocínio de modelos racionais de precificação de ativos está condicionado a relações lineares entre a dispersão do retorno e o retorno de mercado. Quando as relações lineares não se mantiverem, existe a presença do efeito manada. Ou seja, se o coeficiente do item não linear for significativamente negativo, então o comportamento manada é identificado.

O modelo CSAD busca capturar o efeito manada a partir do entendimento de que em um mercado totalmente eficiente a relação entre as variáveis CSAD e retorno do mercado deveriam ser lineares, ou seja, quando a dispersão do mercado aumentar, espera-se que aconteça a mesma coisa com os seus retornos. Quando os investidores tendem a agir de uma maneira mais homogênea a partir de um comportamento irracional, essa relação linear não acontece. Portanto, o que explica o desvio-padrão absoluto de retorno é o termo não linear, indicando a ocorrência do comportamento de manada no mercado acionário.

Neste trabalho foi utilizada a forma logarítmica para a determinação do retorno, conforme apresentado na equação (3). A escolha de utilização dessa fórmula se deu porque ela faz com que 
a curva de representação dos dados seja menos dispersa, aumentando as chances de que os requisitos de normalidade dos testes de validação dos resultados sejam atingidos. (Macedo, Almeida \& Dornelles, 2016; Soares, Rostagno \& Soares, 2002).

$$
R_{i, t}=\ln \left(\frac{P_{i, t}}{P_{i, t-1}}\right)
$$

em que:

$R_{i, t}=$ Retorno do ativo i, no período t;

$P_{i, t}=$ Preço da ação da empresa i no período t;

$P_{i, t-1}=$ Preço da ação da empresa i no período t-1;

Tendo em vista que as empresas analisadas, neste trabalho, foram as que apresentaram os maiores volumes de negociações na $[\mathrm{B}]^{3}$ - Brasil Bolsa Balcão, por estas comporem o índice $\mathrm{IBrX} 100$, este foi utilizado como referência do retorno médio de mercado. Para tanto, a fim de identificar o índice médio de cada ano analisado, foi realizado o cálculo da média anual por meio dos índices IBrX100 mensais.

No que diz respeito à análise dos fatores que se relacionam com o efeito manada, aplicou-se uma regressão múltipla, tendo o EM (efeito manada) como a variável dependente, as demais variáveis - o tamanho da empresa, o período de crise e a publicação de notícias boas e ruins sobre as empresas - como variáveis explicativas, e o tempo de negociação das ações e o Ibovespa como variáveis de controle. O modelo utilizado, para ilustrar as relações que buscou-se analisar, foi uma adaptação do proposto por Flores, Vieira e Coronel (2013).

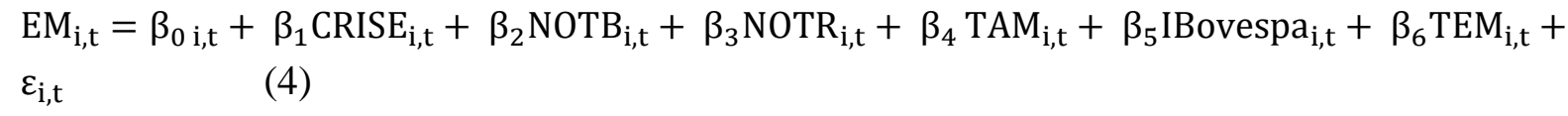

em que:

$\mathrm{EM}_{\mathrm{i}, \mathrm{t}}=$ Variável que representa a presença do efeito manada nos retornos da ação da empresa i no período t, medida por meio do coeficiente do termo não linear (variável $R_{m, t}^{2}$ da equação (2)).

Ao rodar uma regressão OLS com as variáveis estruturadas conforme a equação (2), obtém-se um coeficiente para cada variável do modelo. Para o efeito manada, foram considerados os coeficientes obtidos, por meio da regressão, para o termo não linear (representado pelo $R_{m, t}^{2}$ ) de cada uma das empresas analisadas em cada ano.

$\mathrm{CRISE}_{\mathrm{i}, \mathrm{t}}=$ Períodos de crise financeira (considerada como variável dummy para representar períodos de crise/restrições financeiras, assumindo valor 1 para o período de 2008 e 2009 e valor 0 para os demais períodos), atribuído para cada empresa i no período $t$.

NOTB $_{i, t}=$ Publicação de notícias boas sobre a empresa i, divulgadas nos sites dos três jornais no período t.

NOTR $_{i, t}=$ Publicação de notícias ruins sobre a empresa i analisadas nos sites dos três jornais no período t.

$\mathrm{TAM}_{\mathrm{i}, \mathrm{t}}=$ Tamanho da empresa i (calculado por meio do logaritmo neperiano do patrimônio líquido das empresas), no período t.

IBovespa $_{\mathrm{i}, \mathrm{t}}=$ Índice de retornos da $[\mathrm{B}]^{3}-$ Representa o comportamento do mercado de ações para cada empresa i no período t; foi incluído por demonstrar os reflexos dos efeitos causados pelos períodos de crise financeira no rendimento do mercado (Santana \& Trovati, 2014).

$\mathrm{TEM}_{\mathrm{i}, \mathrm{t}}=$ Período de negociações das ações da empresa i (calculado por meio do logaritmo neperiano do total de dias desde o início de negociações das ações até o último dia de análise, ou seja, desde a data do IPO até o final de cada ano analisado), no período t.

$\varepsilon_{\mathrm{i}, \mathrm{t}}=$ Erros do modelo. 
De maneira geral, a proposta na equação 2 foi identificar a presença do efeito manada no mercado financeiro brasileiro. Após ser identificado tal efeito, a equação (4) propôs a análise de possíveis fatores (variáveis) que podem explicar e se relacionar com a ocorrência de tal comportamento.

A fim de testar as hipóteses da pesquisa, buscando verificar a relação dos fatores propostos no modelo com o comportamento manada, utilizou-se a análise de regressão por meio do modelo de dados em painel com erros-padrão robustos, o qual foi identificado como o mais adequado por meio dos testes de Chow, Hausman e Breusch-Pagan. Sarlo Neto, Lopes e Dalmácio (2010) relatam que esses testes são utilizados para identificar a seleção da abordagem que oferece a melhor especificação. Cada um deles possui finalidades diferentes e são utilizados em diferentes pares de especificações. Inicialmente, se aplica o teste de Breusch-Pagan entre os modelos pooled e efeitos aleatórios. Caso haja a rejeição da hipótese nula pelo teste de Breusch-Pagan, há a necessidade da aplicação do teste de Hausman para a escolha entre os efeitos fixos (EF) e aleatórios (EA).

Conforme Marques (2000), o modelo de dados em painel apresenta a vantagem de sugerir a existência de características que diferenciam os indivíduos, podendo ser constante ou não ao longo do tempo, e isso contribui para se evitar resultados enviesados.

\section{APRESENTAÇÃO E ANÁLISE DOS RESULTADOS}

A partir da observação da estatística descritiva, conforme demonstrado na Tabela 1, percebese que os dados com as maiores dispersões em torno de suas médias foram os das variáveis tempo de negociação das ações e tamanho; seus valores são 2,305 e 1,753, respectivamente. Isto revela que a amostra de empresas estudada apresenta elevada dispersão, tanto nos dados do tamanho das companhias quanto nos do tempo de negociação de suas ações.

O distanciamento da média também pode ser confirmado por meio da comparação entre os valores máximos e mínimos de tais variáveis. Da mesma forma, vale ressaltar que a variável EM, que representa a presença do efeito manada, evidenciou, por meio do seu desvio-padrão $(0,008)$, que os valores de comportamento manada nas empresas tenderam a se aproximar da média, ou seja, apresentaram baixa dispersão.

Tabela 1

Estatística descritiva das variáveis do modelo

\begin{tabular}{lcccccc}
\hline \multicolumn{1}{c}{ Variável } & Média & Moda & Mediana & Desvio-padrão & Máximo & Mínimo \\
\hline Efeito manada (EM) & 0,102 & 0,104 & 0,101 & 0,008 & 0,182 & 0,051 \\
Crise & 0,196 & 0 & 0 & 0,397 & 1 & 0 \\
Notícias boas & 1,083 & 1 & 1 & 0,794 & 3 & 0 \\
Notícias ruins & 0,945 & 1 & 1 & 0,799 & 3 & 0 \\
Tamanho & 22,160 & 24,136 & 22,072 & 1,753 & 26,575 & 4,605 \\
Ibovespa & 10,929 & 10,991 & 10,896 & 0,086 & 11,112 & 10,801 \\
Tempo de negociação & 7,518 & 0 & 7,937 & 2,305 & 10,244 & 0 \\
\hline
\end{tabular}

Fonte: Dados da pesquisa (2017).

Os valores máximos e mínimos expressos na Tabela 1, tanto da variável tamanho quanto da variável tempo de negociação, apresentaram um grande intervalo. Isso evidencia que as suas médias não apresentam uma informação muito representativa sobre a amostra. Em relação à média do Ibovespa, como essa variável apresentou um baixo desvio-padrão e um intervalo pequeno entre os valores mínimos e máximos, isso indica que a média representou bem as informações encontradas para esse índice. $\mathrm{O}$ baixo valor médio obtido para o EM pode ser justificado por se 
tratar do quociente da divisão, na qual o divisor foi considerado o total das 100 empresas analisadas, subtraído de 1 .

Do mesmo modo, a média das notícias boas $(1,083)$ superou a das notícias ruins $(0,945)$, evidenciando a existência de mais informes positivos do que negativos sobre as empresas analisadas. Observa-se, também, que existe diferença significativa entre a média e a mediana das variáveis EM, tamanho, Ibovespa e tempo de negociação, indicando que a distribuição dos dados é assimétrica.

Com o intuito de verificar se a regressão ordinary least squares (OLS) (traduzida por "mínimos quadrados ordinários") apresentava multicolinearidade, foi realizado o teste por meio do Fator de Inflação da Variância (VIF). Segundo Field (2009), um modelo não revela multicolinearidade entre as variáveis quando os valores do VIF estão todos abaixo de 10. A Tabela 2 apresenta o resultado do VIF para as variáveis. Tendo em vista que os valores não se apresentaram maiores ou iguais a 10, entende-se que não foi verificada a existência de multicolinearidade entre as variáveis do modelo.

Tabela 2

\section{Testes de multicolinearidade}

\begin{tabular}{lccccccc}
\hline \multirow{2}{*}{ Teste } & \multicolumn{9}{c}{ Variáveis } \\
\cline { 2 - 8 } & Notícias boas & Notícias ruins & Tempo de negociação & Tamanho & Crise & Ibovespa & Média do VIF \\
\hline VIF & 2,49 & 2,49 & 1,26 & 1,22 & 1,07 & 1,05 & $\mathbf{1 , 6 0}$ \\
\hline
\end{tabular}

Fonte: Dados da pesquisa (2017).

A fim de testar a existência de heterocedasticidade no modelo utilizado, realizou-se o teste de Breusch-Pagan-Godfrey, que forneceu um resultado baseado na estatística qui-quadrado. O teste detecta qualquer forma linear de heterocedasticidade e considera que os resíduos não são normais (Gujarati \& Porter, 2011). Por meio dele, foi verificado que o modelo é heterocedástico, tendo em vista que foi rejeitada, a $1 \%$ de significância, a hipótese nula de ocorrência de homocedasticidade (Prob > chi2 $=0,00$ ).

O resultado também foi evidenciado por meio do teste de White, pois foi obtido um p-valor próximo de zero; por isso, foi rejeitada a hipótese de teste na qual se afirmou a ocorrência de homocedasticidade. Este teste é tido como um teste mais geral e não apresenta problema se a heterocedasticidade for não linear, pois detecta a heterocedasticidade tanto linear quanto não linear. Ele considera que os resíduos não são normalmente distribuídos (Gujarati \& Porter, 2011). Diante dessas evidências, utilizou-se a correção robusta de White, na qual foram ajustados os erros-padrão a partir da heterocedasticidade identificada no modelo.

Os valores expressos na Tabela 3 revelam o resultado da regressão do modelo de dados em painel com estimação robusta. A partir da observação tanto do sinal positivo encontrado para o coeficiente da variável crise quanto do valor obtido no seu p-valor, que se revelou estatisticamente significativo a 1\%, infere-se a não rejeição da hipótese 1, em que se afirmou a existência de relação positiva entre a ocorrência do efeito manada e o período de crise nas empresas com os maiores volumes de negociações listadas na $[\mathrm{B}]^{3}$ - Brasil Bolsa Balcão.

Os achados para a variável crise descrevem que, em períodos de incertezas econômicas, os investidores tendem a seguir as decisões e o comportamento dos grupos maiores. Este resultado corrobora com o encontrado no estudo de Badhuri e Mahapatra (2013), no qual também foi identificada uma relação positiva entre o período de crise e a ocorrência do comportamento manada. Dzielinski (2011) relata também, em sua pesquisa, que nesses momentos os investidores ficam mais expostos a informações negativas e inesperadas sobre as companhias, o que pode justificar a tendência de eles apresentarem um comportamento semelhante ao dos grandes grupos. 
Tabela 3

\section{Resultado da regressão do modelo de dados em painel com efeitos fixos e erro-padrão} robusto

\begin{tabular}{|c|c|c|c|c|c|}
\hline Variável & Coeficiente & Erro-padrão & Razão-t & P-valor & \\
\hline Crise & 0,00480095 & 0,000766056 & 6,2671 & 0,0000 & *** \\
\hline Notícias boas & 0,000795001 & 0,000339673 & 2,3405 & 0,0195 & $* *$ \\
\hline Notícias ruins & $-0,000523282$ & 0,00046789 & $-1,1184$ & 0,2637 & \\
\hline Tamanho & $-0,000151803$ & $7,00196 \mathrm{e}^{-05}$ & $-2,1680$ & 0,0304 & $* *$ \\
\hline Ibovespa & $-0,0116387$ & 0,00114066 & $-10,2035$ & 0,0000 & $* * *$ \\
\hline Tempo de negociação & 0,000266282 & 0,00010074 & 2,6433 & 0,0083 & $* * *$ \\
\hline Constante & 0,228853 & 0,0115979 & 19,7322 & $<0,0001$ & $* * *$ \\
\hline \multirow{2}{*}{$\begin{array}{l}\text { Soma dos resíduos quadrados } \\
\qquad \mathrm{R}^{2}\end{array}$} & \multicolumn{2}{|c|}{0,063088} & D. P. var. dependente & \multicolumn{2}{|c|}{0,008501} \\
\hline & \multicolumn{2}{|c|}{$7,72 \%$} & E. P. da regressão & \multicolumn{2}{|c|}{0,008197} \\
\hline Wooldridge & \multicolumn{2}{|c|}{ Prob $>$ chi $2=2,5 \%$} & $\mathrm{R}^{2}$ ajustado & \multicolumn{2}{|c|}{0,0754} \\
\hline Breusch-Pagan-Godfrey & \multicolumn{2}{|c|}{ Prob $>$ chi $2=0,0$} & White & \multicolumn{2}{|c|}{0,0} \\
\hline
\end{tabular}

Nota. $* * *=$ estatisticamente significativo a $1 \% \mathrm{e}^{* *}=$ estatisticamente significativo a $5 \%$.

Fonte: Dados da pesquisa (2017).

O resultado obtido no teste de significância para a variável notícias boas revelou-se, por meio do p-valor $(0,0195)$, estatisticamente significativo a $5 \%$. Tendo em vista que também foi encontrado um sinal positivo para o coeficiente desta variável, sugere-se a não rejeição da hipótese 2, pois foi evidenciada a ocorrência de relação positiva entre a presença do efeito manada e a publicação de notícias boas sobre as empresas analisadas. Isso indica que a divulgação de informes positivos nos jornais de maior circulação no Brasil referentes às empresas analisadas influencia, positivamente, para que os investidores do mercado financeiro apresentem o comportamento manada.

A conclusão obtida para a variável Notícias Boas evidenciou conformidade com o estudo de Marsden, Veeraraghavan e Ye (2008), no qual também foi identificado que a divulgação de notícias positivas sobre as companhias de capital aberto tende a elevar o otimismo dos analistas, fazendo com que eles façam suas previsões considerando aumentos exagerados em seus lucros e, por isso, são motivados a aplicar seus recursos nas empresas que revelam maiores quantidades de informes positivos. A conclusão também se assemelhou aos achados da pesquisa de Amir e Ganzach (1998), em que os autores descreveram que a exposição dos investidores a boas notícias tende a despertar excesso de otimismo.

A variável Notícias Ruins, mesmo tendo relevado um coeficiente com o sinal negativo esperado, não se apresentou estatisticamente significativa (p-valor > 0,26); logo, a hipótese de existência de relação negativa entre a presença do efeito manada e a publicação de Notícias Ruins foi rejeitada. Este resultado mostrou-se divergente do encontrado no estudo de Damodaran (2010), no qual foi indicado que a presença de notícias ruins tende a ocasionar um viés comportamental nos investidores avesso à perda - essa divergência pode ser justificada por esse trabalho ter analisado outro mercado, investigado o comportamento dos investidores e gestores e considerado outro intervalo de tempo.

Em um estudo dos autores Kremer e Nautz (2013) percebeu-se que os investidores amadores exibiram o comportamento de manada, e que este apresentou relação com o fator "tamanho do ativo". Outrossim, Tariki (2014), em sua análise, identificou indícios de que a intensidade do efeito manada varia conforme o tamanho do fundo de investimento.

Em conformidade com os resultados supracitados, os valores expressos na Tabela 3 descrevem que a variável tamanho se apresentou estatisticamente significativa a $5 \%$ (p-valor $=$ 0,03 ), indicando a existência de relação entre o comportamento manada e o tamanho das empresas com os maiores volumes de negociações listadas na $[\mathrm{B}]^{3}-$ Brasil Bolsa Balcão. Percebeu-se também, por meio do sinal do coeficiente, que essa relação é negativa. No entanto, esse resultado 
diverge do achado no estudo de Lakonishok, Shleifer e Vishny (1992), que encontrou pouca evidência de relação entre o tamanho das ações (ativos) e o comportamento manada.

Tendo em vista que a variável notícias boas apresentou-se com influência positiva no efeito manada, enquanto que a variável notícias ruins não indicou significância - e por isso, não pôde ser atribuída influência sobre o comportamento manada -, isto evidencia que os investidores do mercado brasileiro tendem a apresentar um comportamento mais otimista, no qual consideram, em suas tomadas de decisões de investimento, mais as notícias boas sobre as empresas do que as notícias ruins.

No que diz respeito às variáveis Ibovespa e tempo de negociação, ambas se mostraram estatisticamente significativas a $1 \%$; entretanto, o Ibovespa evidenciou uma relação negativa com o comportamento manada, enquanto que o tempo de negociação das ações apresentou uma relação positiva. Por isso, entende-se que quanto maior o tempo de negociação das ações das empresas na bolsa, maior tende a ser a ocorrência do efeito manada; o inverso acontece com o Ibovespa.

Os valores encontrados para o coeficiente de determinação da regressão $\mathrm{R}^{2}$ descrevem que, de acordo com o teste $\mathrm{F}$, o modelo apresentou baixo poder explicativo, pois indicou que as variáveis independentes do modelo conseguem explicar, conjuntamente, apenas $7,7 \%$ das variações identificadas no comportamento manada.

Com o propósito de verificar a autocorrelação das variáveis do modelo de dados em painel com efeitos fixos e erro-padrão robusto, também foi aplicado o teste de Wooldridge, cujo resultado encontrado evidenciou a inexistência de autocorrelação entre as variáveis (Prob > chi2 apresentou um valor alto e superior a 2\%). Diante disso, não se rejeitou a hipótese nula de inexistência de autocorrelação em detrimento da rejeição da hipótese de autocorrelação. Este resultado evidencia que os erros do modelo não indicaram a presença de um nível de autocorrelação significativo. Assim, a hipótese de independência dos erros foi satisfeita, pois não foi verificada multicolinearidade nos resíduos, e, por isso, a hipótese de teste possui um elevado grau de satisfação.

\section{CONSIDERAÇÕES FINAIS}

Os resultados obtidos evidenciaram a existência de relação positiva entre a presença do efeito manada e o período de crise e as notícias boas. Com isso, entende-se que, em períodos de incertezas econômicas, os investidores tendem a se mostrar mais inseguros e, por isso, buscam agir em conformidade com os grupos maiores. Dzielinski (2011) também observou, em seu estudo, que o período de crise influencia no comportamento dos investidores. Igualmente, Badhuri e Mahapatra (2013) identificaram que nesses períodos o comportamento manada é mais evidenciado.

É evidente que as crises financeiras impactam no comportamento dos investidores. A relação positiva do período de crise com o comportamento manada pode ser explicada pelo fato de que nestes períodos os investidores encontram mais dificuldade em analisar as empresas e identificar os riscos inerentes a cada opção de investimento. Dessa forma, optam por uma conformidade com o mercado, suprimindo suas análises e informações pessoais e buscando um desempenho que se assemelha ao dos outros investidores. Isso desencadeia o efeito manada.

A relação positiva observada na variável notícias boas indica que a divulgação de informes positivos sobre as empresas também influencia nas decisões de investimentos dos agentes que compõem o mercado acionário. Isto pode ser justificado pelo fato de que esses informes tendem a gerar um excesso de otimismo nos investidores e, com isso, a motivá-los a aplicar os seus recursos nas companhias com imagem mais positiva. Este resultado revela conformidade com os achados nos estudos de Marsden, Veeraraghavan e Ye (2008), Amir e Ganzach (1998), e Cutler, Porteba e Summers (1989).

As notícias positivas podem causar um viés comportamental nos investidores, levando-os a ser mais otimistas em suas avaliações de investimento e a crer que a empresa que apresenta o maior volume de informes favoráveis pode ser a melhor opção de investimento. No entanto, as notícias 
não são consideradas as melhores fontes de informações para as tomadas de decisões, pois as próprias companhias podem lançar mão delas para influenciar as expectativas do mercado, a fim de maximizar sua utilidade.

Nesta pesquisa, ainda, foi verificada a existência de relação entre o efeito manada, o tamanho das empresas e o tempo de negociação das suas ações, indicando que os investidores também se influenciam, nas suas decisões de investimentos, tanto pelo porte da empresa quanto pelo período de tempo que ela negocia suas ações no mercado acionário, nas suas decisões de investimentos. No que diz respeito à relação entre o tamanho da empresa e o efeito manada, ela também foi observada por Kremer e Nautz (2013) e Tariki (2014).

No que concerne ao aspecto tamanho, uma possível justificativa para a relação encontrada pode ser o fato de que empresas menores são consideradas mais arriscadas, por conta dos incentivos que possuem para gerenciar suas informações, promovendo maior assimetria informacional e gerando problemas nas avaliações. Os investidores especulativos, por sua vez, são mais propensos ao risco. Ao fazermos uma associação, possivelmente o efeito manada foi mais evidente nas empresas menores por seus investidores apresentarem um perfil mais especulativo.

Considerando que o efeito manada sinaliza que as decisões de investimentos em alguns momentos são realizadas sem uma explicação racional, entende-se que ele é um fator nocivo ao mercado, pois um dos pressupostos da hipótese de eficiência de mercado é a utilização da racionalidade nas escolhas de investimentos.

No desenvolvimento da pesquisa observou-se a existência de limitações, tais como a subjetividade na identificação das notícias boas e ruins (pois foi utilizada a análise de conteúdo, que pode ter contribuído para a não significância estatística apresentada na variável Notícias Ruins); o modelo utilizado; e a quantidade de variáveis consideradas. Diante disso, sugere-se, para futuras pesquisas, o acréscimo de outras variáveis que possam se relacionar com o comportamento manada, a aplicação de outros modelos e o estudo de diferentes amostras de empresas.

Diante do exposto, conclui-se que, apesar das limitações identificadas no estudo, os resultados obtidos contribuíram para o alcance do objetivo, pois identificou-se a presença do efeito manada. Verificou-se a existência de relação entre esse comportamento e o período da crise do subprime, a publicação de notícias boas e o tamanho da empresa, como também a inexistência de relação entre o efeito e a publicação de notícias ruins. Por isso, considera-se que foi alcançado o objetivo do trabalho e respondeu-se à questão da pesquisa.

\section{REFERÊNCIAS}

Agnew, J. R., \& Szykman, L. R. (2005). Asset allocation and information overload: the influence of information display, asset choice, and investor experience. The Journal of Behavioral Finance, 6(2), 57-70.

Almeida, R. P. (2011). O comportamento manada em mercados acionários latino-americanos. Dissertação de mestrado em Administração, Universidade Federal de Santa Catarina (UFSC), Florianópolis, Santa Catarina, Brasil.

Amir, E., \& Ganzach Y. (1998). Overreaction and underreaction in analysts forecasts. Journal of Economic Behavior and Organization, 37, 333-347.

Araujo Neto, L. M. de, Serrano, A. L. M., Oliveira Neto, J. C. da C., Freitas, R. L. C. de \& Abreu, E. S. de. (2016). Efeito manada no mercado de capitais: um estudo com gerentes de bancos públicos do Distrito Federal. Revista de Administração, Contabilidade e Economia, 15(2), 601-620. 
Ariely, D. (2008). Previsivelmente irracional: as forças ocultas que formam as nossas decisões. Tradução de Jussara Simões. Rio de Janeiro: Elsevier.

Arruda, P. B. (2006). Uma investigação sobre o efeito disposição. Dissertação de Mestrado em Engenharia de Produção, Universidade Federal de Santa Catarina, Florianópolis, SC, Brasil.

Banerjee, A. V. (1992). A simple model of herd behavior. Quarterly Journal of Economics, 107(3), 797-817.

Barberis, N., \& Thaler, R. (2003). A survey of Behavioural Finance. Working Paper Series, 1, 1053-1128.

Bastos, E. de S., Rosa, M. P., \& Pimenta, M. M. (2016). Os impactos da Operação Lava Jato e da crise internacional do petróleo nos retorno anormais e indicadores contábeis da Petrobras 2012-2015. Pensar Contábil, 18(67), 49-56.

Bhaduri, S. N., \& Mahapatra, S. D. (2013). Applying an alternative test of herding behavior: A case study of the Indian stock Market. Journal of Asian Economics, 25, 43-52.

Bikhchandani, S., Hirshleifer, D., \& Welch I. (1992). A theory of fads, fashion, custom, and cultural change as informational cascades. Journal of Political Economy, 100(5), 992-1026.

Bikhchandani, S., \& Sharma, S. (2001). Herd Behavior in Financial Markets. IMF Staff Papers, 47(3) 279-310.

Borsato, J. M. L. S., Costa, R. B. da, Pimenta, D. P., \& Ribeiro, K. C. de S. (2009). Otimismo e excesso de confiança: Um estudo do perfil comportamental dos indivíduos, à luz das finanças comportamentais. Anais do SemeAd, São Paulo, SP, Brasil, 12.

Chang, E., Cheng, J., \& Khorana, A. (2004). An examination of herd behavior in equity markets: an international perspective. Journal of Banking \& Finance, 24, 1651-1679.

Chiang, T. C., \& Dazhi, Z. (2010). An empirical analysis of herd behavior in global stock markets. Journal of Banking \& Finance, 34, 1911-1921.

Chiao, C., Hung, W., \& Lee, C. F. (2011). Institutional, trading and opening price behavior: evidence from a fast emerging market. Journal of Financial Research, 34(1), 131-154.

Choi, N., \& Sias, R. W. (2009). Institutional industry herding. Journal of Financial Economics, 94(3), 469-491.

Christie, W. G., \& Huang, R. D. (1999). Following the pied piper: do individual returns herd around the market? Financial Analysts Journal, 51(4), 31-37.

Cont, R., \& Bouchaud, J-P. (2000). Herd behavior and aggregate fluctuations in financial markets. Microeconomic Dynamics, 4, 170-196.

Cutler, D. M., Porteba, J. M., \& Summers, L. H. (1989). What moves stock prices? Journal of Portifolio Management, 15(3), 4-12. 
Delitala, M., \& Lorenzi, T. (2014) A mathematical model for value estimation with public information and herding. Kinetic and Related Models, 7(1), 29-44.

Damodaran, A. (2010). Equity Risk Premiums (ERP): Determinants, Estimation and Imprications. Stern School of Business, 1-89.

During, B. Juengel, A., \& Trussardi, L. (2017). A kinetic equation for economic value estimation with irrationality dnd herding. Kinetic and Related Models, 10(1), 239-261.

Dzielinski, M. (2011). News sensitivity and the cross-section of stock returns. Social Science Research Network, Rochester, NY. Recuperado em 19 janeiro, 2017, de http://www.zora.uzh.ch/49785/4/Dzielinski_New_sensivity_and_the_crosssection_of_stock_returns-V.pdf

Field, A. (2009). Descobrindo a estatística usando o SPSS (2a ed.). Porto Alegre, RS, Brasil.

Flores, S. A. M., Vieira, K. M., \& Coronel, D. A. (2013). Influência de fatores comportamentais na propensão ao endividamento. R. Adm. FACES Journal Belo Horizonte. 12(2),13-35.

Fu, T. \& Lin, M. (2010). Herding in China equity market. International. Journal of Economics and Finance, 2(2), 148-156.

Gil, A. C. (2010). Como Elaborar Projetos de Pesquisa (5a ed.). São Paulo, SP, Brasil.

Halfeld, M., \& Torres, F. de F. L. (2001) Finanças comportamentais: aplicações no contexto brasileiro. Revista de Administração de Empresas, 41(2), 64-71.

Gujarati, D. N., \& Dawn C. P. (2011). Econometria Básica (5a ed.). Porto Alegre: AMGH.

Hwang, S., \& Salmon, M. (2001). A New Measure of Herding and Empirical Evidence. Financial Econometrics research Centre - Working Papers Series. London, England.

Hwang, S., \& Salmon, M. (2004). Market stress and herding. Journal of Empirical Finance, 11(4), 585-616.

Kahneman, D., \& Tversky, A. (1979) Prospect Theory: an analysis of decision under risk. Econometrica, 47(2), $263-292$.

Keynes, J. M. (1936). The general theory of employment, interest and money. London: Macmillan.

Kimura, H. (2003). Aspectos comportamentais associados às reações do mercado de capitais. Revista de Administração de Empresas (RAE), 2(1), 2-14.

Kremer, S., \& Nautz, D. (2013). Causes and consequences of short-term institutional herding. Journal of Banking and Finance, 37(5) 1676-1686.

Kutchukian, E. (2010). O efeito manada nos fundos de investimento no Brasil: um teste em finanças comportamentais. Dissertação de mestrado em Administração, Fundação Getúlio Vargas (FGV), São Paulo, SP, Brasil. 
Kutchukian, E., Dana, S., \& Eid Jr., W. (2010). O Efeito Manada nas captações de fundos de investimento no Brasil entre 2005 e 2009. Anais do Encontro Brasileiro de Finanças, 10. Recuperado em $21 \quad$ janeiro, $2017, \quad$ de http://bibliotecadigital.fgv.br/ocs/index.php/ebf/10EBF/paper/view/1921/1010

Lakonishok, J., Shleifer, A., \& Vishny, R. W. (1992). The impact of institutional trading on stock prices. Journal of Financial Economics, 32(1), 23-43.

Lam, C. F., Derue, D. S., Karam, E. P., \& Hollenbeck, J. R. (2011). The impact of feedback frequency on learning and task performance: challenging the more is better assumption. Organizational Behavior and Human Decision Processes, 116(2), 217-228.

Leone, R. J. G., \& Guimarães, T. C. (2012). O comportamento financeiro durante e após a crise financeira de 2008 sob a ótica da teoria dos prospectos. Revista de Contabilidade do Mestrado em Ciências Contábeis da UERJ, 17(3), 119-140.

Lobão, J., \& Serra, A. P. (2002). Herding behavior: evidence from Portuguese mutual funds. Working paper. Recuperado em 23 janeiro, 2017, de http://www.fep.up.pt/investigacao/cempre/actividades/sem_fin/sem_fin_01/PAPERS_PDF /paper_sem_fin_20jun02.pdf

Lucena, W. G. L., Costa, A. M. M., \& Aragão, F. B. (2013). Finanças Comportamentais: Evidências do benefício da aquisição de medicamentos genéricos na população de Caruaru/PE. InterScience Place, 1, 139-162.

Lucena, W. G. L., Santos, J. M. A., Assis, J. T., \& Santos, M. C. (2014). Fatores que influenciam o endividamento e a inadimplência no Setor Imobiliário da cidade de Toritama-PE à luz das Finanças Comportamentais. Holos, 6, 90-113.

Macedo, M. A. da S., Almeida, J. E. F. de, \& Dornelles, O. M. (2016). Os mercados acionários internacionais reagem mais às demonstrações contábeis ou às notícias? $\mathrm{O}$ caso do escândalo do Banco HSBC. Pensar Contábil, 18(67), 5-22.

Marques, L. D. (2000). Modelos Dinâmicos com Dados em Painel: Revisão de Literatura. Working Paper, Faculdade de Economia do Porto. Recuperado em 7 janeiro, 2017, de http://www.fep.up.pt/investigacao/workingpapers/wp100.pdf

Marsden, A., Veeraraghavan, M., \& Ye, M. (2008). Heuristics of Representativeness, Anchoring and Adjustment, and Leniency: Impact on Earnings Forecasts by Australian Analysts. Journal of Finance and Accounting, 47(2), 83-102.

Menard, S. (2002). Applied logistic regression analysis (Vol. 106). Sage.

Passos, J. C., Pereira, V. S. \& Martins, V. F. (2012). Contextualizando a pesquisa em Finanças Comportamentais: Uma análise das principais publicações nacionais e internacionais que abrange o período de 1997 a 2010. Revista de Auditoria, Governança e Contabilidade (RAGC), 1(1), 38-60.

Puckett, A, \& Yan, X. S. (2008). Short-Term Institutional Herding and its Impacto on Stock Prices, in SSRN Electronic Journal. Recuperado em 24 janeiro, 2017, de 
https://www.researchgate.net/publication/228267058_Short-

Term_Institutional_Herding_and_its_Impact_on_Stock_Prices

Ricciardi, V., \& Simon, H. K. (2000). What is behaioral finance? The Business, Education and Technology Journal, 2(2) 26-34.

Rogers, P., Securato, J. R., \& de Sousa Ribeiro, K. C. (2007). Finanças comportamentais no Brasil: um estudo comparativo. Revista de Economia e Administração, 6(1).

Roth, G. C., Albuquerque, A. A. D., \& Silva, D. M. D. (2012). Uma análise dos impactos causados pela alteração do rating soberano sobre o retorno das ações das dez empresas com maior volume de negociações na BM\&FBOVESPA. In Congresso USP de Controladoria e Contabilidade (Vol. 12).

Sanches, M. V. (2013). Comportamento de manada em direção ao índice de mercado: evidências no mercado brasileiro de ações. Dissertação de mestrado em Administração de Empresas, Universidade de São Paulo, São Paulo, SP, Brasil.

Santana, V. de F., \& Trovati, L. M. (2014). Pessimismo nas segundas-feiras: uma análise do efeito dia da semana no mercado de capitais brasileiro em períodos de crise e de estabilidade. Revista de Gestão, Finanças e Contabilidade, 4 (2), 38-53.

Sarlo Neto, A., Lopes, A. B., \& Dalmácio. F. Z. (2010). A influência da estrutura de propriedade sobre a informatividade dos lucros contábeis divulgados pelas empresas negociadas na Bovespa. Base - Revista de Administração e Contabilidade da Unisinos, 7(4), 301-314.

Sewell, M. (2007). Behavioural Finance. University College London.

Shih, T., Hsu, A., Yang, S., \& Lee, Chien-Chiang. (2012). Empirical research of herding behavior in the Pacific Basin stock markets: Evidence from the U.S. stock market rise (drop) in succession. Procedia - Social and Behavioral Sciences, 40, 7-15.

Sias, R. (2004). Institutional Herding. The Review of Financial Studies, 17(1), 165-206.

Silva, J. X. S. da., Barbedo, C. H. da S., \& Araújo, G. S. (2015). Há Efeito Manada em Ações com Alta Liquidez do Mercado Brasileiro? Trabalhos para Discussão, Banco Central do Brasil, 1-19. Recuperado em 20 janeiro, 2017, de https://www.bcb.gov.br/pec/wps/port/TD386.pdf

Soares, R. O., Rostagno, L. M., \& Soares, K. T. C. (2002). Estudo de evento: o método e as formas de cálculo do retorno anormal. Anais do Encontro Nacional dos Programas de PósGraduação em Administração, 27, 30-33.

Tarik, F. R. (2014). Evidência do efeito manada em fundos de renda variável na indústria de fundos brasileira. Dissertação do mestrado em Macroeconomia, Fundação Getúlio Vargas (FGV/EESP), São Paulo, SP, Brasil.

Teh, L. \& Debondt, W. F.M. (1997). Herding behavior and stock returns: an exploratory investigation. Swiss Journal of Economics and Statistics, 133, 293- 324. 
Tibúrcio, C. A. S., Carvalho, C. C. de., \& Nunes, D. M. S. (2012). O que move o preço da ação? Uma abordagem sobre a influência das notícias no mercado acionário. REUNIR - Revista de Administração, Contabilidade e Sustentabilidade, 2(3), 1-13

Toscani, G. (2006). Kinetic models of opinion formation. Communications in Mathematical Sciences, 4(3), 481-496

Venezia, I., Nashikkar, A., \& Shapira, Z. (2011). Firm specific and macro herding by professional and amateur investors and their effects on market volatility. Journal of Banking \& Finance, 35(7), 1599-1609.

Yao, J., MA, C. \& HE, W. P. (2014). Investor herding behaviour of Chinese stock market. International Review of Economics \& Finance, 29, 12-29.

Zhou, J., Anderson, R. (2013) I. An empirical investigation of herding behavior in the U.S. REIT Market. Journal of Real Estate Finance and Economics, 47(1), 83-108. 